\title{
Persepsi Dan Preferensi Pengguna Terhadap Prasarana dan Perlengkapan Jalan di Kawasan Lapangan Puputan Margarana
}

\author{
Xand Conery Prabowo ${ }^{1}$, Ni Luh Made Pradnyawathi ${ }^{2}$, I Gusti Agung Ayu Rai Asmiwyati ${ }^{1}$ \\ 1. Program Studi Arsitekur Lanskap, Fakultas Pertanian, Universitas Udayana, Indonesia 80236 \\ 2. Program Studi Agroekoteknologi, Fakultas Pertanian, Universitas Udayana, Indonesia 80236
}

*E-mail: npradnyawathi@yahoo.com

\begin{abstract}
User perceptions and preferences on road infrastructure and equipment at region of Lapangan Puputan Margarana. Denpasar is one of the most populated city in Bali. The density is caused mainly by the rapidly increasing population that affects the traffic growth in Denpasar. The Puputan Margarana Square has been the venue for entertainment, recreation and sport activities for the people of Denpasar. Being the meeting point of several streets, has made Puputan Margarana quite crowded that it needs to be balanced and equipped with sufficient supporting roads and facilities in the area. The purpose of the research is to measure the perception and preference of the user on the safety and comfort of the facilities in the areas (Jalan Ir. H. Juanda, Jalan Basuki Rahmat, dan Jalan Kusuma Atmaja). The research method used was survey method by the technique in this research was a direct observation, interviews and questionnaires. Based on the research, it was revealed that the perception of the users on the safety and comfort of the accessibility and circulation, sidewalks, crossing area, parking area and other road equipment in the Puputan Margarana square are considered to be sufficiently safe and comfortable. User's preference indicates that further arrangement and addition of several supporting facilities is still required. The research result is a recommendation on the several street facilities and equipment and also hoped to be a reference information for the related institutions.
\end{abstract}

Keywords: Comfort, Road Utility, Road Infrastructure, Safety

\section{Pendahuluan}

Kawasan lapangan Puputan Margarana dijadikan sebagai salah satu tempat aktivitas hiburan, rekreasi, dan olahraga bagi masyarakat Kota Denpasar. Kawasan Lapangan Puputan Margarana merupakan titik pusat pertemuan antara berbagai ruas jalan. Pada ruas-ruas jalan ini terdapat pusat pemerintahan yang berada di Jalan Basuki Rahmat dan Jalan Kusuma Atmaja, serta pusat fasilitas pelayanan masyarakat di Jalan Ir. $\mathrm{H}$. Juanda. Kawasan Lapangan Puputan Margarana sebagai kawasan pertemuan antara berbagai jalan menjadikan kawasan ini padat dan perlu adanya keseimbangan prasarana dan perlengkapan jalan pendukung yang ada pada ruas jalan di kawasan tersebut.

Kawasan Lapangan Puputan Margarana tentunya masih memiliki kelebihan dan kekurangan dalam aspek keamanan dan kenyamanan pada prasarana dan perlengkapan jalan. Dengan adanya penerapan standar prasarana dan perlengkapan jalan dengan baik, diharapkan tata kelola yang akan datang juga menghasilkan kepuasan pengguna jalan sebagai pihak yang menggunakan. Tata kelola itu sendiri pada pemerintah Kota Denpasar juga harus melakukan pengelolaan yang baik terhadap prasarana dan perlengkapan jalan, karena harus memperhatikan kondisi lingkungan dan kebutuhan pengguna serta apa yang diharapkan atau apa yang melebihi dari harapan pengguna terhadap prasarana dan perlengkapan jalan di kawasan tersebut.

Penelitian ini bertujuan untuk mengukur persepsi dan preferensi pengunjung terhadap keamanan dan kenyamanan prasarana dan perlengkapan jalan yang meliputi aksesibilitas dan sirkulasi, trotoar, area penyeberangan, area parkir, serta perabotan jalan di kawasan Lapangan Puputan Margarana, dan memberikan rekomendasi beberapa prasarana dan perlengkapan jalan, serta diharapkan sebagai informasi dan acuan kepada pihak dan dinas terkait. 


\section{Metode}

Penelitian ini berlokasi pada ruas Jalan Kusuma Atmaja, Jalan Basuki Rahmat, Jalan Ir. H. Juanda di kawasan lapangan Puputan Margarana, Desa Sumerta Kelod, Kecamatan Denpasar Timur, Bali (Gambar 1). Penelitian ini dilakukan selama lima bulan yaitu mulai dari bulan Juli 2019 sampai dengan bulan November 2019.

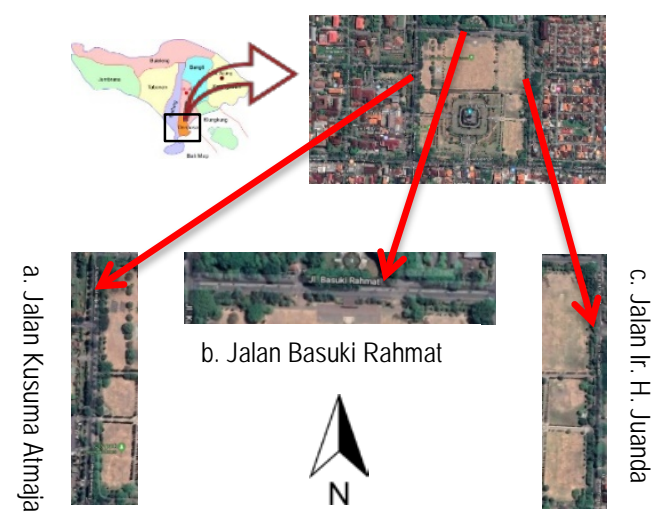

Gambar 1. Denah Lokasi penelitian Sumber: (Google, 2019)

\section{$2.2 \quad$ Alat}

Alat yang digunakan dalam penelitian ini adalah kamera, laptop, alat tulis dan dibantu dengan perangkat lunak penunjang seperti software Google Earth, Adobe photoshop, Microsoft Office Word, Microsoft Office Excel, dan lembar kuisioner.

\subsection{Metode Penelitian}

Metode penelitian yang digunakan adalah metode survei dengan melakukan teknik pengumpulan data berupa data primer melalui observasi, wawancara, dan kuisioner, dan data sekunder berupa studi pustaka. Metode analisis yang digunakan adalah metode deskriptif.

\subsection{Metode Analisis}

Metode pengelolaan data yang digunakan dalam mengolah data hasil kuisioner dalam penelitian ini adalah tabulasi data dalam bentuk persentase (\%).

\subsection{Tahapan Penelitian}

Penelitian dimulai dari menentukan responden berdasarkan teknik pengambilan sampel dengan metode nonprobability sampling dengan jumlah total 90 pengguna jalan di kawasan lapangan Puputan Margarana yang masing-masing 30 responden pada setiap ruas jalan. Responden menilai keamanan dan kenyamanan terhadap prasarana dan perlengkapan jalan di kawasan lapangan Puputan Margarana, kemudian dilanjutkan dengan analisis, sintesis, dan berakhir pada tahap rekomendasi. Pada penelitian ini dibatasi hanya kepada pengguna jalan yang pernah dan sedang melintasi ruas jalan di kawasan lapangan Puputan Margarana (Jalan Kusuma Atmaja, Jalan Basuki Rahmat, dan Jalan Ir. H. Juanda). Penelitian dibatasi pada persepsi dan prefensi pengguna terhadap keamanan dan kenyamanan prasarana dan perlengkapan jalan di kawasan Lapangan Puputan Margarana Kota Denpasar.

\section{Hasil dan Pembahasan}

\subsection{Gambaran Umum Lokasi Penelitian}

Pada kawasan lapangan Puputan Margarana terdapat beberapa ruas jalan yang saling bersinggungan diantaranya seperti Jalan Kusuma Atmaja, Jalan Basuki Rahmat, Jalan Ir. H. Juanda yang memiliki fungsi beraneka ragam yaitu seperti perkantoran, pendidikan, dan jasa. Selain digunakan sesuai fungsi di atas, penggunaan jalan tersebut juga dimanfaatkan sebagai akses untuk berolahraga, seperti jogging, senam, dan kegiatan lainnya, sehingga terdapat berbagai golongan pengguna jalur pedestrian, termasuk oleh PNS, pegawai swasta, karyawan, siswa, mahasiswa, dan masyarakat umum.

\subsection{Aksesibilitas dan Sirkulasi}

Akses menuju kawasan Lapangan Puputan Margarana dapat melalui beberapa jalan, termasuk Jalan Raya Puputan, Jalan Cok Agung Tresna, Jalan Letjen S. Parman, Jalan Prof Yamin, dan Jalan Dr. Muwardi. 
Selain itu, di sekitar kawasan Lapangan Puputan Margarana, terdapat areal permukiman warga, areal pelayanan masyarakat, dan areal pusat pemerintahan Provinsi Bali.

\subsection{Prasarana dan Perlengkapan Jalan}

Persyaratan jalan wajib dillengkapi dengan rambu, marka, alat pemberi isyarat, alat pengendali dan alat pengaman pemakai jalan, alat pengawasan dan pengaman jalan serta fasilitas pendukung lainnya. Sarana perlengkapan jalan bertujuan untuk keselamatan, keamanan, ketertiban dan kelancaran lalu lintas serta kemudahan pemakaian jalan. Beberapa prasarana dan perlengkapan jalan yang ada pada kawasan lapangan Puputan Margarana yaitu trotoar, jalur penyeberangan (zebra cross), area parkir, dan fasilitas pelengkap jalan (street furniture).

\subsection{Trotoar}

Kondisi trotoar di Jalan Ir. H. Juanda yang kurang bagus disebabkan oleh karena terdapat beberapa komponen trotoar yang terlepas, sehingga untuk kondisi trotoar seperti ini mesti dilakukan perbaikan yang signifikan guna untuk mencapai keamanan dan kenyamanan pengguna trotoar. Selain itu, terdapat kerusakan pada pinggir trotoar di Jalan Basuki Rahmat yang diakibatkan oleh akar pohon. Hal ini bisa membahayakan pejalan kaki baik dari segi keamanan dan kenyamanan trotoar, sehingga perlu dilakukan perbaikan yang berkala untuk mengembalikan fungsi dari trotoar tersebut. Selanjutnya, terlihat trotoar di Jalan Kusuma Atmaja dengan kondisi cukup bagus sehingga keamanan dan kenyamanan pengguna trotoar dapat tercapai. Hanya saja lebar trotoar yang kurang lebar diakibatkan sebagian lahan digunakan sebagai lahan parkir.

\subsection{Jalur Penyeberangan (Zebra Cross)}

Pada Jalan Ir. H. Juanda terlihat menghilangnya atau memudarnya garis zebra cross sehingga akan dapat mengganggu keamanan serta kenyamanan pengguna jalan dalam menyeberang ataupun berkendara. Kondisi jalur penyeberangan di Jalan Basuki Rahmat masih terlihat bagus namun dari segi garis zebra cross masih perlu dilakukan perbaikan untuk memperjelas batas zebra cross guna untuk pengguna jalan serta pengendara agar dapat tercapai keamanan dan kenyamanan yang ditentukan. Terdapat zebra cross di Jalan Kusuma Atmaja yang terlihat memudar sehingga akan dapat mengganggu keamanan serta kenyamanan pengguna jalan, sama seperti hal nya yang terjadi pada Jalan Ir. H. Juanda.

\subsection{Parkir}

Terdapat area parkir di Jalan Ir. H. Juanda yang sudah tertata dengan baik ditandai dengan tersedianya lahan parkir untuk mobil yang menyebabkan lalu lintas tetap lancar dan ada hambatan dari kendaraan yang parkir sembarangan. Oleh karena itu, untuk kedepannya hanya dilakukan kontrol saja untuk mencegah kendaraan yang parkir di luar area parkir. Pada area parkir di Jalan Basuki Rahmat terlihat bahwa sebagian jalan raya digunakan sebagai lahan parkir. Dalam hal ini, penataan kendaraan untuk parkir masih tergolong rapi sehingga akan membuat kenyamanan yang cukup baik untuk lalu lintas di Jalan Basuki Rahmat. Selain itu, pada Jalan Kusuma atmaja memiliki lahan parkir yang tertata dengan baik sehingga tidak ada kendaraan yang parkir sembarangan. Hal ini perlu dipertahankan dengan cara melakukan kontrol untuk kendaraan yang parkir sembarangan terutama pada jam-jam sibuk.

\section{7 $\quad$ Street Furniture (Fasilitas Pelengkap Jalan)}

Street furniture atau yang sering disebut "fasilitas pelengkap jalan" merupakan salah satu elemen pendukung kegiatan pada suatu ruang publik berupa ruas jalan yang akan memperkuat karakter suatu blok perancangan yang lebih besar (Permen PU no. 6 tahun 2007). Terdapat beberapa street furniture di Jalan Ir. $H$. Juanda di antaranya rambu-rambu jalan, tempat sampah, dan lampu jalan. Namun terdapat rambu jalan yang masih kurang jelas sehingga diperlukan perbaruan untuk meningkatkan keamanan dan kenyamanan pengendara jalan. Terlihat bahwa street furniture yang ada di Jalan Basuki Rahmat tergolong lengkap disebabkan oleh karena terdapat rambu-rambu jalan, lampu lalu lintas, CCTV, serta tempat sampah dan juga setiap street furniture dalam kondisi bagus dan layak pakai. Kondisi street furniture di Jalan Kusuma Atmaja masih dalam kondisi yang baik dan dengan fungsi yang baik. Kelengkapan street furniture ini mempengaruhi keamanan dan kenyamanan pengendara tetap terjaga dan menghindari kecelakaan lalu lintas di sekitar jalan tersebut.

\subsection{Karakteristik Responden}

Karakteristik responden dikelompokkan berdasarkan usia, tingkat pendidikan, pekerjaan utama, frekuensi kunjungan, waktu kunjungan, jenis aktivitas, serta moda transportasi yang digunakan responden. 
Informasi tersebut untuk mengetahui kebutuhan dan kelayakan prasrana dan perlengkapan jalan terhadap pengguna jalan.

\subsection{Persepsi Responden}

Menurut Slameto (2010), persepsi adalah proses yang menyangkut masuknya pesan atau informasi ke dalam otak manusia. Kemudian, Sobur (2003) menyebutkan bahwa persepsi dapat merupakan proses menerima, menyeleksi, mengorganisasikan, mengartikan, menguji, dan memberikan reaksi kepada rangsangan panca indera atau data. Penelitian ini juga dilakukan penilaian atau evaluasi persepsi responden mengenai kondisi kenyamanan terhadap prasarana dan perlengkapan jalan di Jalan Ir.H Juanda, Jalan Basuki Rahmat, dan Jalan Kusuma Atmaja. Adapun parameter yang digunakan dalam penilaian persepsi responden adalah kondisi keamanan dan kenyamanan. Berikut merupakan hasil kuisioner mengenai persepsi responden mengenai sirkulasi keluar masuk jalan, kelancaran sirkulasi, ketersediaan parkir, kejelasan keberadaan rambu parkir, trotoar, zebra cross, aksesibilitas menuju kawasan jalan dan kemudahan akses dari ruas jalan lain yang dinilai melalui parameter kenyamanan dan keamanan pada setiap jalan. Keamanan merupakan suatu kondisi terhindar dari resiko kecelakaan selama berlalu lintas yang disebabkan oleh manusia, kendaraan, jalan dan/atau lingkungan (UU No. 22 Tahun 2009).

Tabel 1. Indikator Persepsi Responden Mengenai Kondisi Keamanan di Jalan Ir. H. Juanda

\begin{tabular}{clccccc}
\hline No & \multicolumn{1}{c}{ Kriteria Penilaian } & STS & TS & CS & S & SS \\
\hline 1 & Sirkulasi keluar masuk yang disediakan sudah aman & $3,3 \%$ & - & $20 \%$ & $63,3 \%$ & $13,3 \%$ \\
2 & Sirkulasi (keluar - masuk) berjalan dengan lancar & - & $3,3 \%$ & $16,6 \%$ & $63,3 \%$ & $16,6 \%$ \\
3 & $\begin{array}{l}\text { Pusat parkir yang tersedia sudah aman (lalu lintas, tindak kriminal, } \\
\text { dan pohon tumbang) }\end{array}$ & $6,6 \%$ & $13,3 \%$ & $16,6 \%$ & $53,3 \%$ & $10 \%$ \\
4 & $\begin{array}{l}\text { Rambu lalu lintas yang tersedia sudah cukup jelas dan berada pada } \\
\text { penempatan yang benar }\end{array}$ & - & $6,7 \%$ & $40 \%$ & $36,6 \%$ & $16,6 \%$ \\
5 & $\begin{array}{l}\text { Trotoar (pejalan kaki) sudah terakomodasi dengan baik dan } \\
\text { memadai }\end{array}$ & - & $16,6 \%$ & $23,3 \%$ & $43,3 \%$ & $16,6 \%$ \\
6 & $\begin{array}{l}\text { Trotoar yang tersedia sudah aman (lalu lintas, tindak kriminal, pohon } \\
\text { tumbang, dan struktur material trotoar) }\end{array}$ & - & $6,7 \%$ & $23,3 \%$ & $56,6 \%$ & $13,3 \%$ \\
7 & $\begin{array}{l}\text { Zebra Cross (jalur penyeberangan) sudah terakomodasi dengan } \\
\text { baik dan memadai }\end{array}$ & - & $13,3 \%$ & $16,6 \%$ & $46,7 \%$ & $23,3 \%$ \\
8 & $\begin{array}{l}\text { Zebra Cross yang tersedia sudah aman digunakan pada saat } \\
\text { menyeberang (gangguan lalu lintas) }\end{array}$ & - & $6,7 \%$ & $26,6 \%$ & $46,7 \%$ & $20 \%$ \\
\hline
\end{tabular}

Keterangan: STS = Sangat Tidak Setuju, TS = Tidak Setuju, CS = Cukup Setuju, S = Setuju. SS = Sangat Setuju

Tabel 2. Indikator Persepsi Responden Mengenai Kondisi Kenyamanan di Jalan Ir. H. Juanda

\begin{tabular}{|c|c|c|c|c|c|c|}
\hline No & Kriteria Penilaian & STS & TS & CS & S & SS \\
\hline 1 & $\begin{array}{l}\text { Aksesibilitas menuju kawasan berjalan dengan lancar dan cukup } \\
\text { nyaman }\end{array}$ & - & - & $20 \%$ & $70 \%$ & $10 \%$ \\
\hline 2 & Akses dari ruas jalan lain mudah dan sudah berjalan dengan baik & - & $3,3 \%$ & $30 \%$ & $60 \%$ & $6,7 \%$ \\
\hline 3 & $\begin{array}{l}\text { Area parkir yang tersedia sudah rapi dan cukup nyaman (keteduhan } \\
\text { pohon, jalur keluar masuk) }\end{array}$ & - & $13,3 \%$ & $36,6 \%$ & $43,3 \%$ & $6,7 \%$ \\
\hline 4 & $\begin{array}{l}\text { Area parkir yang disediakan sudah terakomodasi dengan baik } \\
\text { (jumlah kapasitas parkir) }\end{array}$ & - & $16,6 \%$ & $53,3 \%$ & $30 \%$ & - \\
\hline 5 & $\begin{array}{l}\text { Trotoar (pejalan kaki) sudah Terakomodasi dengan baik dan } \\
\text { memadai }\end{array}$ & - & $10 \%$ & $30 \%$ & $53,3 \%$ & $6,7 \%$ \\
\hline 6 & $\begin{array}{l}\text { Trotoar yang telah tersedia sudah cukup nyaman untuk digunakan } \\
\text { (lalu lintas, keteduhan pohon, kondisi trotoar) }\end{array}$ & - & $6,7 \%$ & $23,3 \%$ & $63,3 \%$ & $6,7 \%$ \\
\hline 7 & $\begin{array}{l}\text { Zebra cross (jalur penyeberangan) sudah terakomodasi dengan baik } \\
\text { dan memadai }\end{array}$ & $3,3 \%$ & $10 \%$ & $23,3 \%$ & $56,6 \%$ & $6,7 \%$ \\
\hline 8 & $\begin{array}{l}\text { Zebra cross sudah nyaman digunakan pada saat menyeberang } \\
\text { (rambu penyeberangan, zona tanda penyeberangan) }\end{array}$ & $3,3 \%$ & $13,3 \%$ & $30 \%$ & $43,3 \%$ & $10 \%$ \\
\hline 9 & $\begin{array}{l}\text { Perabotan jalan (street furniture) sudah terakomodasi dengan baik } \\
\text { dan memadai }\end{array}$ & $3,3 \%$ & $20 \%$ & $36,6 \%$ & $26,6 \%$ & $13,3 \%$ \\
\hline 10 & $\begin{array}{l}\text { Perabotan jalan (street furniture) yang tersedia sudah cukup } \\
\text { nyaman dan mudah digunakan }\end{array}$ & $3,3 \%$ & $6,7 \%$ & $43,3 \%$ & $46,7 \%$ & \\
\hline
\end{tabular}

Keterangan: STS = Sangat Tidak Setuju, TS = Tidak Setuju, CS = Cukup Setuju, S = Setuju. SS = Sangat Setuju

Berikut merupakan hasil analisis gabungan mengenai persepsi responden terhadap kondisi keamanan dan kenyamanan prasarana dan perlengkapan jalan di Jalan Ir. H. Juanda:

1. Aksesibilitas dan Sirkulasi 
Persentase tertinggi dari kondisi keamanan mengenai sirkulasi keluar masuk di sepanjang jalur pedestrian di Jalan Ir. H. Juanda dinilai aman oleh responden dengan nilai persentase $63,3 \%$ dan persentase tertinggi kondisi kenyamanan $70 \%$ menyatakan setuju (S). Sebagian besar responden $(63,3 \%)$ menyatakan setuju (S) terhadap kelancaran sirkulasi keluar masuk. Kenyamanan dan kelancaran aksesibilitas di Jalan Ir. $\mathrm{H}$. Juanda dan kemudahan akses dari jalan lain mendapatkan persentase setuju (S) tertinggi melalui penilaian persepsi responden, yang menjelaskan bahwa mayoritas responden setuju dan memberikan sikap positif terhadap kenyamanan dan kelancaran aksesibilitas, kemudahan akses dari satu jalan menuju jalan lain, keamanan sirkulasi serta kelancaran sirkulasi di jalan Ir. H. Juanda.

\section{Area Parkir}

Persentase tertinggi menunjukkan bahwa 53\% responden cukup setuju (CS) jika area parkir telah terakomodasi dengan baik dan pada penempatan yang benar, termasuk penyesuaian terhadap kapasitas area parkir terhadap jumlah masyarakat yang parkir kendaraan. Kondisi ini telah memungkinkan tercapainya keamanan dan kenyamanan terhadap keberadaan area parkir, dengan masing masing persepsi responden setuju (S) yaitu 53,3\% dan 43,3\%. Terdapat pusat area parkir dengan ukuran cukup luas yang disediakan oleh pemerintah untuk kendaraan berupa roda dua dan roda empat. Secara visual, area parkir ini memang memenuhi kriteria nyaman dan kenyamanan area parkir. Namun, berdasarkan hasil observasi, area parkir ini memang kurang dimanfaatkan oleh masyarakat, bahkan yang memiliki keperluan di dekat area ini. Masyarakat cenderung memanfaatkan area parkir bermotor yang terdapat di sepanjang sisi jalan maupun sisi Lapangan Puputan Margarana, yang mungkin disebabkan karena masyarakat cenderung menginginkan area yang lebih dekat dengan tempat aktivitas yang diperlukan.

\section{Trotoar}

Persentase tertinggi mengenai trotoar telah terakomodasi dengan baik dan pada penempatan yang benar dinilai setuju (S) dengan nilai $43,3 \%$. Kondisi ini telah memungkinkan tercapainya keamanan dan kenyamanan terhadap keberadaan trotoar, dengan masing-masing persepsi setuju dari responden, yaitu $56,6 \%$ dan $63,3 \%$. Faktor keamanan dinilai dari struktural material trotoar, penyesuaian terhadap lalu lintas, terhindar dari tindak kriminal, dan terhindar dari pohon tumbang.

\section{Jalur Penyeberangan (Zebra Cross)}

Persentase tertinggi mengenai kenyamanan zebra cross dinilai setuju oleh responden (S) dengan nilai $43,3 \%$. Penilaian tersebut karena pejalan kaki mendapat prioritas yang baik saat menyeberang jalan sehingga akan merasa nyaman. Persentase tertinggi untuk kondisi keamanan terhadap ketepatan penempatan jalur penyeberangan adalah sebesar $46,7 \%$. Persentase tersebut didapat karena pelanggar yang melalui jalan tersebut tergolong sedikit sehingga pejalan kaki merasa aman untuk menggunakan zebra cross untuk menyeberang.

\section{Fasilitas Pelengkap Jalan (Street Furniture)}

Persentasi tertinggi mengenai kenyamanan dan kemudahan dalam menggunakan fasilitas pelengkap jalan (street furniture) adalah sebesesar 46,7\% menyatakan setuju (S), sehingga dapat dijelaskan bahwa mayoritas responden memiliki persepsi positif. Persentase tertinggi dari aspek kenyamanan mengenai sudah terakomodasi dan memadai memiliki nilai $36,6 \%$ menyatakan cukup setuju (CS). Hal ini disebabkan karena perlengkapan jalan yang masih belum lengkap atau dianggap kurang memadai oleh responden, seperti kurangnya papan informasi (signage), kurangnya tempat sampah, serta kurangnya tiang pembatas jalan/bollards pada lokasi yang berbahaya.

Tabel 3. Indikator Persepsi Responden Mengenai Kondisi Keamanan di Jalan Basuki Rahmat

\begin{tabular}{|c|c|c|c|c|c|c|}
\hline No & Kriteria Penilaian & STS & TS & CS & $\mathbf{S}$ & SS \\
\hline 1 & Sirkulasi keluar masuk yang disediakan sudah aman & $3,3 \%$ & $23,3 \%$ & $43,3 \%$ & $23,3 \%$ & $6,7 \%$ \\
\hline 2 & Sirkulasi (keluar - masuk) berjalan dengan lancar & $10 \%$ & $16,6 \%$ & $50 \%$ & $20 \%$ & $3,3 \%$ \\
\hline 3 & $\begin{array}{l}\text { Pusat parkir yang tersedia sudah aman (lalu lintas, tindak } \\
\text { kriminal, dan pohon tumbang) }\end{array}$ & $10 \%$ & $40 \%$ & $30 \%$ & $20 \%$ & - \\
\hline 4 & $\begin{array}{l}\text { Rambu lalu lintas yang tersedia sudah cukup jelas dan berada } \\
\text { pada penempatan yang benar }\end{array}$ & $26,6 \%$ & $43,3 \%$ & $20 \%$ & $10 \%$ & - \\
\hline 5 & $\begin{array}{l}\text { Trotoar (pejalan kaki) sudah terakomodasi dengan baik dan } \\
\text { memadai }\end{array}$ & $13,3 \%$ & $53,3 \%$ & $26,6 \%$ & $6,7 \%$ & - \\
\hline
\end{tabular}




\begin{tabular}{clccccc}
\hline No & \multicolumn{1}{c}{ Kriteria Penilaian } & STS & TS & CS & S & SS \\
\hline 6 & $\begin{array}{l}\text { Trotoar yang tersedia sudah aman (lalu lintas, tindak kriminal, } \\
\text { pohon tumbang, dan struktur material trotoar) }\end{array}$ & $13,3 \%$ & $60 \%$ & $20 \%$ & $6,7 \%$ & - \\
7 & $\begin{array}{l}\text { Zebra Cross (jalur penyeberangan) sudah terakomodasi dengan } \\
\text { baik dan memadai }\end{array}$ & $30 \%$ & $36,6 \%$ & $33,3 \%$ & - & - \\
8 & $\begin{array}{l}\text { Zebra Cross yang tersedia sudah aman digunakan pada saat } \\
\text { menyeberang (gangguan lalu lintas) }\end{array}$ & $23,3 \%$ & $43,3 \%$ & $30 \%$ & $3,3 \%$ & - \\
\hline
\end{tabular}

Keterangan: STS = Sangat Tidak Setuju, TS = Tidak Setuju, CS = Cukup Setuju, S = Setuju. SS = Sangat Setuju Tabel 4. Indikator Persepsi Responden Mengenai Kondisi Kenyamanan di Jalan Basuki Rahmat

\begin{tabular}{|c|c|c|c|c|c|c|}
\hline No & Kriteria Penilaian & STS & TS & CS & $\mathbf{S}$ & SS \\
\hline 1 & $\begin{array}{l}\text { Aksesibilitas menuju kawasan berjalan dengan lancar dan cukup } \\
\text { nyaman }\end{array}$ & - & $6,6 \%$ & $56,6 \%$ & $36,6 \%$ & - \\
\hline 2 & Akses dari ruas jalan lain mudah dan sudah berjalan dengan baik & - & $16,6 \%$ & $53,3 \%$ & $23 \%$ & $6,7 \%$ \\
\hline 3 & $\begin{array}{l}\text { Area parkir yang tersedia sudah rapi dan cukup nyaman } \\
\text { (keteduhan pohon, jalur keluar masuk) }\end{array}$ & $10 \%$ & $43,3 \%$ & $43,3 \%$ & $3,3 \%$ & - \\
\hline 4 & $\begin{array}{l}\text { Area parkir yang disediakan sudah terakomodasi dengan baik } \\
\text { (jumlah kapasitas parkir) }\end{array}$ & $10 \%$ & $46,7 \%$ & $40 \%$ & $3,3 \%$ & - \\
\hline 5 & $\begin{array}{l}\text { Trotoar (pejalan kaki) sudah terakomodasi dengan baik dan } \\
\text { memadai }\end{array}$ & $13,3 \%$ & $60 \%$ & $26,6 \%$ & - & - \\
\hline 6 & $\begin{array}{l}\text { Trotoar yang telah tersedia sudah cukup nyaman untuk digunakan } \\
\text { (lalu lintas, keteduhan pohon, kondisi trotoar) }\end{array}$ & $16,6 \%$ & $46,7 \%$ & $33,3 \%$ & $3,3 \%$ & - \\
\hline 7 & $\begin{array}{l}\text { Zebra cross (jalur penyeberangan) sudah terakomodasi dengan } \\
\text { baik dan memadai }\end{array}$ & $6,7 \%$ & $53,3 \%$ & $40 \%$ & - & - \\
\hline 8 & $\begin{array}{l}\text { Zebra cross sudah nyaman digunakan pada saat menyeberang } \\
\text { (rambu penyeberangan, zona tanda penyeberangan) }\end{array}$ & $10 \%$ & $66,6 \%$ & $20 \%$ & $3,3 \%$ & - \\
\hline 9 & $\begin{array}{l}\text { Perabotan jalan (street furniture) sudah terakomodasi dengan baik } \\
\text { dan memadai }\end{array}$ & $6,7 \%$ & $53,3 \%$ & $40 \%$ & - & - \\
\hline 10 & $\begin{array}{l}\text { Perabotan jalan (street furniture) yang tersedia sudah cukup } \\
\text { nyaman dan mudah digunakan }\end{array}$ & $13,3 \%$ & $40 \%$ & $43,3 \%$ & $3,3 \%$ & - \\
\hline
\end{tabular}

Keterangan: STS = Sangat Tidak Setuju, TS = Tidak Setuju, CS = Cukup Setuju, S = Setuju. SS = Sangat Setuju

Berikut merupakan hasil analisis gabungan mengenai persepsi responden terhadap kondisi keamanan dan kenyamanan prasarana dan perlengkapan jalan di Jalan Basuki Rahmat:

1. Aksesibilitas dan Sirkulasi

Persentase tertinggi dari kondisi keamanan mengenai sirkulasi keluar masuk di sepanjang jalur pedestrian di Jalan Basuki Rahmat dinilai cukup aman oleh responden dengan nilai persentase $43,3 \%$ dan persentase tertinggi kondisi kenyamanan aksesibilitas $56,6 \%$ menyatakan cukup setuju (CS). Selain itu, sebagian besar responden menyatakan cukup setuju (CS) terhadap kelancaran sirkulasi keluar masuk dengan nilai 50\%, yang mana hal ini akan berkorelasi positif terhadap peningkatan rasa nyaman atau kenyamanan pejalan kaki.

\section{Area Parkir}

Persentase tertinggi menunjukkan bahwa 40\% responden tidak setuju (TS) terhadap keamanan area parkir. Kondisi ini memengaruhi tingkat kenyamanan responden terhadap area parkir dengan menyatakan tidak setuju $(43,3 \%)$ yang menunjukkan bahwa sebagian besar responden memberikan persepsi negatif. Selain itu ada 46,7\% responden tidak setuju (TS) jika area parkir telah terakomodasi dengan baik dan pada penempatan yang benar, termasuk penyesuaian terhadap kapasitas area parkir terhadap jumlah masyarakat yang parkir kendaraan.

3. Trotoar

Persentase tertinggi mengenai keamanan trotoar responden memiliki persepsi negatif dengan memberikan penilaian tidak setuju (TS) sebesar $60 \%$. Hal ini kemungkinan disebabkan oleh penempatan trotoar yang belum memadai. Hal ini dibuktikan dari hasil persepsi responden menyatakan tidak setuju (TS) sebesar 60\% terhadap penempatan trotoar. Terdapat sekitar 46,7\% responden tidak setuju (TS) mengenai kenyamanan trotoar, kondisi ini menjadi akibat karena penempatan trotoar yang dinilai belum benar dan tidak memadai serta kenyamanan yang dinilai masih kurang. Faktor keamanan dinilai dari struktural material trotoar, penyesuaian terhadapa lalu lintas, terhindar dari tindakan kriminal, dan terhindar dari pohon tumbang.

4. Jalur Penyeberangan (Zebra Cross)

Persentase tertinggi mengenai zebra cross telah terakomodasi dengan baik dinilai tidak setuju (TS) oleh responden dengan nilai $36,6 \%$ dan dari kondisi kenyamanan mengenai zebra cross dinilai tidak nyaman 
dengan nilai sebesar $66,7 \%$. Penilaian tersebut disebabkan oleh karena pejalan kaki masih kurang mendapat prioritas yang baik saat menyeberang jalan sehingga kurang merasa nyaman. Selain itu, persentase untuk kondisi keamanan dinilai tidak aman oleh responden dengan nilai sebesar $43,3 \%$. Selanjutnya, persentase mengenai ketersediaan zebra cross dirasa kurang memadai oleh responden dengan nilai sebesar $53,3 \%$. Persentase ini menunjukkan, bahwa mayoritas responden memiliki persepsi bahwa penempatan zebra cross masih kurang tepat, sehingga hal tersebut menyebabkan tingkat kenyamanan responden juga kurang baik.

5. Fasilitas Pelengkap Jalan (Street Furniture)

Persentase tertinggi mengenai street furniture yang terakomodasi dan memadai dinilai tidak setuju (TS) oleh responden dengan nilai sebesar 53,3\%, penilaian tersebut disebabkan oleh karena fasilitas pelengkap jalan yang masih belum lengkap atau kurang memadai, seperti kurangnya papan informasi (signage), kurangnya tempat sampah, tidak tersedianya pengaman pohon, serta tiang pembatas jalan/bollards pada lokasi yang berbahaya.

Persentase tertinggi mengenai persepsi kenyamanan yaitu $43,3 \%$ oleh responden menyatakan cukup setuju (CS) terhadap keberadaan street furniture. Selain itu, responden menilai bahwa penempatan rambu lalu lintas belum memadai dengan nilai sebesar 43,3\%. Namun, karena pada sepanjang Jalan Basuki Rahmat masih terdapat pohon-pohon yang berfungsi sebagai peneduh serta adanya planter box yang masih dalam kondisi cukup baik, sehingga meningkatkan persepsi positif responden terhadap penilaian kenyamanan.

Tabel 5. Indikator Persepsi Responden Mengenai Kondisi Keamanan di Jalan Kusuma Atmaja

\begin{tabular}{clccccc}
\hline No & \multicolumn{1}{c}{ Kriteria Penilaian } & STS & TS & CS & S & SS \\
\hline 1 & Sirkulasi keluar masuk yang disediakan sudah aman & - & - & $46,7 \%$ & $43,3 \%$ & $10 \%$ \\
2 & Sirkulasi (keluar - masuk) berjalan dengan lancar & $3,3 \%$ & $3,3 \%$ & $36,6 \%$ & $53,3 \%$ & $3,3 \%$ \\
3 & $\begin{array}{l}\text { Pusat parkir yang tersedia sudah aman (lalu lintas, tindak kriminal, } \\
\text { dan pohon tumbang) }\end{array}$ & - & $23,3 \%$ & $33,3 \%$ & $33,3 \%$ & $10 \%$ \\
4 & $\begin{array}{l}\text { Rambu lalu lintas yang tersedia sudah cukup jelas dan berada } \\
\text { pada penempatan yang benar }\end{array}$ & $3,3 \%$ & $20 \%$ & $20 \%$ & $36,6 \%$ & $20 \%$ \\
5 & $\begin{array}{l}\text { Trotoar (pejalan kaki) sudah terakomodasi dengan baik dan } \\
\text { memadai }\end{array}$ & $10 \%$ & $20 \%$ & $33,3 \%$ & $13,3 \%$ & $23,3 \%$ \\
6 & $\begin{array}{l}\text { Trotoar yang tersedia sudah aman (lalu lintas, tindak kriminal, } \\
\text { pohon tumbang, dan struktur material trotoar) }\end{array}$ & - & $20 \%$ & $26,6 \%$ & $46,7 \%$ & $6,7 \%$ \\
7 & $\begin{array}{l}\text { Zebra Cross (jalur penyeberangan) sudah terakomodasi dengan } \\
\text { baik dan memadai }\end{array}$ & $3,3 \%$ & $26,6 \%$ & $26,6 \%$ & $40 \%$ & $3,3 \%$ \\
8 & $\begin{array}{l}\text { Zebra Cross yang tersedia sudah aman digunakan pada saat } \\
\text { menyeberang (gangguan lalu lintas) }\end{array}$ & $3,3 \%$ & $16,6 \%$ & $46,7 \%$ & $26,6 \%$ & $6,7 \%$ \\
\hline
\end{tabular}

Keterangan: STS = Sangat Tidak Setuju, TS = Tidak Setuju, CS = Cukup Setuju, S = Setuju. SS = Sangat Setuju Tabel 6. Indikator Persepsi Responden Mengenai Kondisi Kenyamanan di Jalan Kusuma Atmaja

\begin{tabular}{|c|c|c|c|c|c|c|}
\hline No & Kriteria Penilaian & STS & TS & CS & S & SS \\
\hline 1 & $\begin{array}{l}\text { Aksesibilitas menuju kawasan berjalan dengan lancar dan cukup } \\
\text { nyaman }\end{array}$ & $3,3 \%$ & $3,3 \%$ & $20 \%$ & $66,6 \%$ & $6,7 \%$ \\
\hline 2 & Akses dari ruas jalan lain mudah dan sudah berjalan dengan baik & - & $6,6 \%$ & $26,6 \%$ & $63,3 \%$ & $3,3 \%$ \\
\hline 3 & $\begin{array}{l}\text { Area parkir yang tersedia sudah rapi dan cukup nyaman } \\
\text { (keteduhan pohon, jalur keluar masuk) }\end{array}$ & $3,3 \%$ & $16,6 \%$ & $26,6 \%$ & $36,6 \%$ & $16,6 \%$ \\
\hline 4 & $\begin{array}{l}\text { Area parkir yang disediakan sudah terakomodasi dengan baik } \\
\text { (jumlah kapasitas parkir) }\end{array}$ & $6,7 \%$ & $16,6 \%$ & $30 \%$ & $33,3 \%$ & $13,3 \%$ \\
\hline 5 & $\begin{array}{l}\text { Trotoar (pejalan kaki) sudah Terakomodasi dengan baik dan } \\
\text { memadai }\end{array}$ & $6,7 \%$ & $23,3 \%$ & $26,6 \%$ & $33,3 \%$ & $10 \%$ \\
\hline 6 & $\begin{array}{l}\text { Trotoar yang telah tersedia sudah cukup nyaman untuk digunakan } \\
\text { (lalu lintas, keteduhan pohon, kondisi trotoar) }\end{array}$ & - & $20 \%$ & $20 \%$ & $50 \%$ & $10 \%$ \\
\hline 7 & $\begin{array}{l}\text { Zebra cross (jalur penyeberangan) sudah terakomodasi dengan } \\
\text { baik dan memadai }\end{array}$ & $3,3 \%$ & $30 \%$ & $30 \%$ & $30 \%$ & $6,7 \%$ \\
\hline 8 & $\begin{array}{l}\text { Zebra cross sudah nyaman digunakan pada saat menyeberang } \\
\text { (rambu penyeberangan, zona tanda penyeberangan) }\end{array}$ & $3,3 \%$ & $20 \%$ & $50 \%$ & $20 \%$ & $6,7 \%$ \\
\hline 9 & $\begin{array}{l}\text { Perabotan jalan (street furniture) sudah terakomodasi dengan } \\
\text { baik dan memadai }\end{array}$ & - & $10 \%$ & $56,6 \%$ & $26,6 \%$ & $6,7 \%$ \\
\hline 10 & $\begin{array}{l}\text { Perabotan jalan (street furniture) yang tersedia sudah cukup } \\
\text { nyaman dan mudah digunakan }\end{array}$ & - & $13,3 \%$ & $43,3 \%$ & $40 \%$ & $3,3 \%$ \\
\hline
\end{tabular}

Keterangan: STS = Sangat Tidak Setuju, TS = Tidak Setuju, CS = Cukup Setuju, S = Setuju SS = Sangat Setuju

Berikut merupakan hasil analisis gabungan mengenai persepsi responden terhadap kondisi keamanan dan kenyamanan prasarana dan perlengkapan jalan di Jalan Kusuma Atmaja: 


\section{Aksesibilitas dan Sirkulasi}

Persentase tertinggi mengenai kondisi keamanan sirkulasi keluar masuk di sepanjang jalur pedestrian dinilai cukup setuju (CS) oleh responden dengan nilai 46,7\% dan kondisi kenyamanan aksesibilitas menuju Jalan Kusuma Atmaja dengan pernyataan setuju (S) yaitu $66,7 \%$. Selain itu, sebagian besar responden menyatakan setuju (S) terhadap kelancaran sirkulasi keluar masuk dengan persentase sebesar $53,3 \%$. Persentase tertinggi mengenai keamanan dan kelancaran aksesibilitas melalui jaan lain mendapat pernyataan setuju oleh responden dengan nilai $63,3 \%$. Penilaian tersebut disebabkan ruas jalan yang cukup mudah diakses karena telah dilengkapi dengan rambu lalu lintas dan zebra cross.

2. Area Parkir

Persentase tertinggi mengenai area parkir telah terkomodasi dengan baik dan pada penempatan yang benar dinilai setuju (S) oleh responden dengan nilai 33,3\%, termasuk penyesuaian terhadap kapasitas area parkir terhadap jumlah masyarakat yang parkir kendaraan. Kondisi ini telah memungkinkan tercapainya keamanan dan kenyamanan terhadap keberadaan area parkir dengan masing-masing persepsi setuju (S) oleh responden yaitu dengan nilai $33,3 \%$ dan $36,6 \%$.

3. Trotoar

Persentase tertinggi mengenai trotoar telah terakomodasi dengan baik dan pada penempatan yang benar dinilai cukup setuju (CS) dengan nilai 33,3\%. Kondisi ini telah memungkinkan tercapainya keamanan dan dan kenyamanan terhadap keberadaan trotoar, $46,7 \%$ dan 50\% responden menyatakan setuju (S). Terdapat sekitar 33,3\% responden setuju (S) jika trotoar telah dalam penempatan yang benar. Peniliaian tersebut disebabkan oleh karena struktural material trotoar, penyesuaian terhadap lalu lintas, terhindar dari tindakan kriminal, dan terhindar dari pohon tumbang.

4.Jalur Penyeberangan (Zebra Cross)

Persentase tertinggi mengenai zebra cross telah terakomodasi dengan baik dinilai setuju (S) oleh responden dengan nilai $40 \%$. Hasil persentase tertinggi dari kondisi kenyamanan dinilai cukup setuju (CS) dengan nilai 50\%. Selain itu, persentase untuk kondisi keamanan sebesar $46,7 \%$ responden menyatakan cukup aman. Selanjutnya persentase mengenai penempatan zebra cross yang benar, masing-masing dinilai responden dengan perepsi setuju (S), cukup setuju (CS), dan tidak setuju (TS), yaitu 30\%. Persentase ini menunjukkan, bahwa mayoritas responden memiliki persepsi bahwa penempatan zebra cross masih kurang tepat, sehingga hal tersebut berpengaruh terhadap kondisi tingkat kenyamanan responden.

5. Fasilitas Pelengkap Jalan (Street Furniture)

Persentasi tertinggi mengenai street furniture sudah terakomodasi dan memadai dinilai cukup setuju (CS) oleh responden dengan nilai $56,6 \%$. Selain itu, responden menyatakan cukup setuju (CS) terhadap kenyamanan dan kemudahan dalam menggunakan street furniture dengan nilai $43,3 \%$. Kemudian, sebagai salah satu bagian fasilitas pelengkap jalan, mayoritas responden memiliki persepsi positif mengenai penempatan rambu lalu lintas, dengan menyatakan setuju (S) sebesar 36,6\%. Hal ini menjelaskan bahwa street furniture telah sesuai dan bermanfaat bagi pengguna, sehingga dapat meningkatkan keamanan dan kenyamanan pengguna.

\subsection{Preferensi Responden}

Menurut Porteus (1977), studi perilaku individu dapat digunakan oleh ahli lingkungan dan para desainer untuk menilai keinginan pengguna (user) terhadap suatu objek yang akan direncanakan, dengan melihat preferensi dapat memberikan masukan bagi pemangku kepentingan sebagai bentuk partisipasi dalam proses perencanaan. Parameter dari preferensi responden, yaitu ketersediaan area pejalan kaki (trotoar), ketersediaan area penyeberangan (zebra cross), ketersediaan area parkir, ketersediaan perabotoan jalan (street furniture). Berikut merupakan hasil dari preferensi responden mengenai prasarana dan perlengkapan jalan pada Jalan Ir. H. Juanda, Jalan Basuki Rahmat, dan Jalan Kusuma Atmaja.

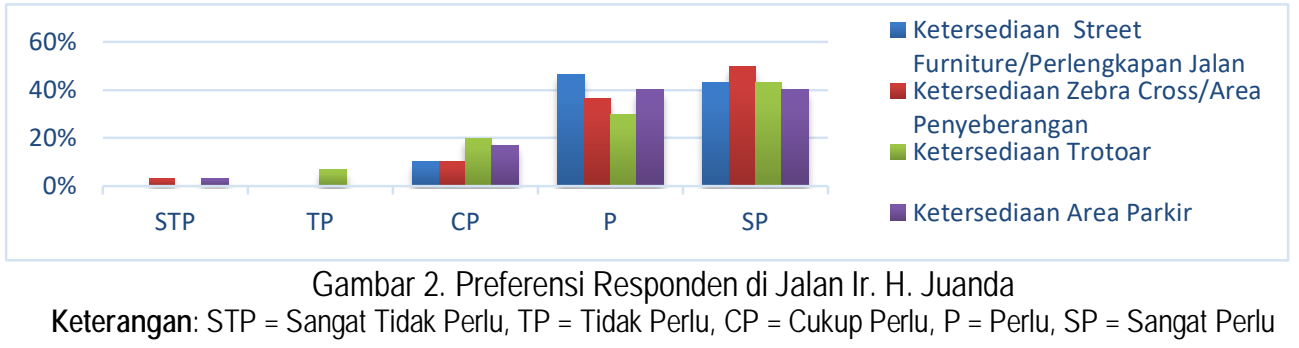




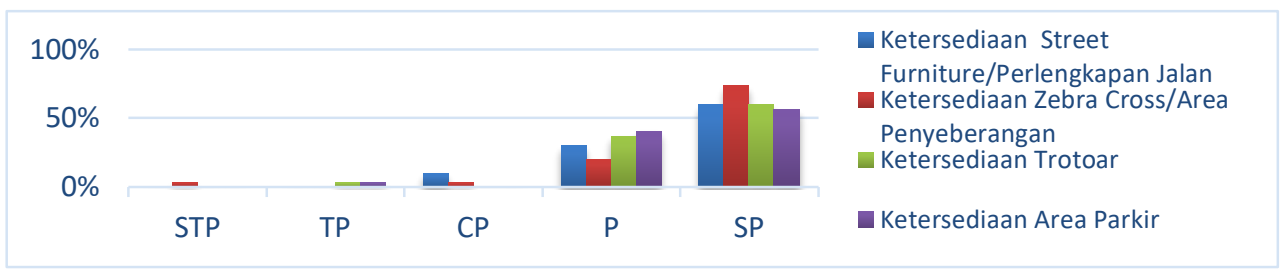

Gambar 3. Preferensi Responden di Jalan Basuki Rahmat

Keterangan: $\mathrm{STP}=$ Sangat Tidak Perlu, $\mathrm{TP}=$ Tidak Perlu, $\mathrm{CP}=$ Cukup Perlu, $\mathrm{P}=\mathrm{Perlu}, \mathrm{SP}=$ Sangat Perlu

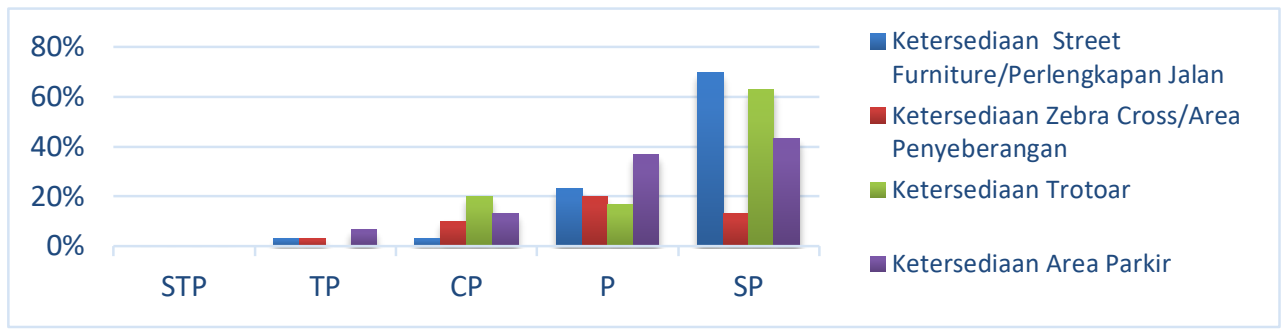

Gambar 4. Preferensi Responden di Jalan Kusuma Atmaja

Keterangan: STP $=$ Sangat Tidak Perlu, $T P=$ Tidak Perlu, $C P=$ Cukup Perlu, $P=$ Perlu, $S P=$ Sangat Perlu

\subsection{Sintesis}

Adapun sintesis mengenai persepsi dan preferensi pengguna terhadap prasarana dan perlengkapan jalan ini adalah berdasarkan analisis terhadap hasil penelitian dan kajian pustaka yang relevan, yaitu dengan melebarkan badan trotoar yang tidak sesuai agar dapat memenuhi aksesibilitas dan sirkulasi. Selain itu dapat dilakukan penertiban secara intensif oleh pemerintah terkait kendaraan yang terparkir sembarangan, sehingga tentu diperlukan penambahan ketersediaan area parkir yang lebih memadai dan dengan penempatan yang benar agar para pengendara kendaraan bermotor dapat mengakses parkir dengan nyaman dan aman, serta tidak mengulang kesalahan untuk kedua kalinya. Hal lain yang dapat dilakukan adalah memperbaiki dan melengkapi street furniture untuk jalur pejalan kaki agar lebih meningkatkan kenyamanan dan keamanan pengguna trotoar. Solusi ini dapat dilakukan salah satunya dengan menambahkan bollard dan planter box pada area trotoar agar menunjang keamanan juga kenyamanan para pejalan kaki yang melintasi trotoar sehingga akan menghambat kendaraan bermotor memasuki kawasan khusus pejalan kaki itu, baik untuk sekadar parkir atau melintasinya. Selain itu penambahan papan informasi juga sangat penting untuk menginformasikan pengguna jalan terkait informasi penting.

Berdasarkan hasil analisis penelitian yang dilakukan melalui pengamatan dengan kuisioner mengenai persepsi dan preferensi kenyamanan dan keamanan pengguna, maka dapat direkomendasikan bahwa untuk jalan yang ditinjau (Jalan Ir. H. Juanda, Basuki Rahmat, dan Jalan Kusuma Atmaja) memerlukan aksesibilitas dan sirkulasi yang cukup agar lebih ditingkatkan lagi, serta perlunya penambahan fasilitas perlengkapan jalan dan area parkir untuk menunjang keperluan pengguna jalan di sekitar jalan yang ditinjau (Gambar 5).

\subsubsection{Rekomendasi Prasarana dan Perlengkapan Jalan}
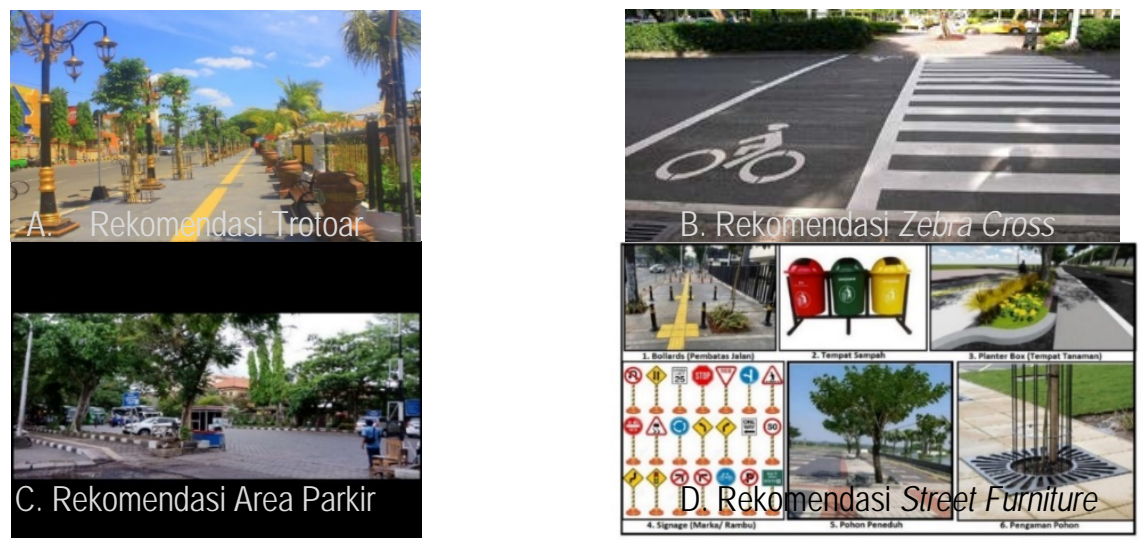

Gambar 5. Rekomendasi Prasarana dan Perlengkapan Jalan 


\section{Simpulan dan Saran}

\subsection{Simpulan}

Berdasarkan hasil analisis data dan sintesis yang telah dilakukan, maka dapat disimpulkan yaitu wujud prasarana dan perlengkapan jalan di kawasan lapangan Puputan Margarana berupa trotoar, penyeberangan jalan (zebra cross), tempat parkir, dan perabotan jalan (street furniture). Pengalaman dan kebiasaan dari mayoritas responden menghasilkan penilaian kondisi keamanan pada kategori cukup aman dengan sebagian besar digolongkan pada kondisi aman dan nyaman. Penilaian tersebut diberikan tanpa respon pemahaman dan pengetahuan tentang pedoman yang berlaku dan tanpa mempertimbangkan pengguna yang tidak aktif menggunakan prasarana dan perlengkapan jalan, sehingga penilaian ini hanya mewakili studi kasus dalam penelitian ini.

Wujud prasarana dan perlengkapan jalan di kawasan lapangan Puputan Margarana berupa trotoar, penyeberangan jalan (zebra cross), tempat parkir, dan street furniture. Prasarana dan perlengkapan jalan tersebut sangat berguna dan dimanfaatkan oleh pengguna jalan. Faktor pengalaman dan kebiasaan responden sebagai faktor yang mempengaruhi penilaian. Responden menyatakan tingkat keamanan serta kenyamanan sarana dana perlengkapan jalan pada kategori cukup aman dan nyaman pada masing-masing elemen jalan. Preferensi atau prioritas yang lebih dibutuhkan pengguna pada prasarana dan perlengkapan jalan terhadap kenyamanan dan keamanan dalam mobilitas adalah ketersediaan area parkir pada Jalan Ir. $\mathrm{H}$. Juanda 40\%, Jalan Basuki Rahmat 56,7\%, Jalan Kusuma Atmaja 43,3\%, kemudian area penyeberangan (zebra cross) pada Jalan Ir. H. Juanda 50\%, Jalan Basuki Rahmat 73,3\%, Jalan Kusuma Atmaja 60\%, kemudian rambu-rambu dan fasilitas pelengkap jalan pada Jalan Ir. H. Juanda 46,7\%, Jalan Basuki Rahmat $60 \%$, dan Jalan Kusuma Atmaja 70\%.

\subsection{Saran}

Berdasarkan simpulan diatas, maka saran yang dapat diberikan untuk meningkatkan kenyamanan dan keamanan pengguna jalan adalah meningkatkan pengelolaan, perawatan atau bahkan menambah fasilitas pendukung oleh pengelola agar prasarana dan perlengkapan jalan di kawasan tersebut berfungsi lebih maksimal. Perlunya penelitian lebih lanjut mengenai perbaikan sarana prasarana jalan serta adanya penambahan perlengkapan jalan di kawasan lapangan Puputan Margarana agar ditingkatkan sesuai kebutuhan kegiatan pengguna jalan.

\section{Daftar Pustaka}

Peraturan Menteri Pekerjaan Umum. (2007). Pedoman Umum Rencana Tata Bangunan dan Lingkungan No. 6 Tahun 2007. Kementrian PU RI. Jakarta.

Porteous JD. (1977). Environmental and Behaviour : Planning and Everyday Urban Life. Addison Weshley Publishing Company. 446. California (USA).

Republik Indonesia. (2009). Undang-Undang Republik Indonesia Nomor 22 Tahun 2009 Tentang Lalu Lintas dan Angkutan Jalan. Menteri Hukum dan HAM. Jakarta.

Slameto. (2010). Belajar Faktor-Faktor Yang Mempengaruhinya. Rineka Cipta. Jakarta.

Sobur, A. (2003). Psikologi Umum. Pustaka Setia. Bandung. 